\title{
A Novel Rapid Visual Detection of Toxoplasma Gondii by Combining Recombinase Polymerase Amplification and Lateral Flow Dipstick Coupled With CRISPR-Cas13a Fluorescence Assay
}

Jinhong Zhao

Wannan Medical College

Yuanyuan Li

Wannan Medical College

Qiqi Xue

Wannan Medical College

Zhiwei Zhu

Wannan Medical College

Minghui Zou

Wannan Medical College

Fang Fang (D 30363754@qq.com )

Wannan Medical College

\section{Research}

Keywords: Toxplasma gondii, recombinase aided amplification, lateral-flow dipstick, CRISPR-Cas13a

Posted Date: August 24th, 2021

DOl: https://doi.org/10.21203/rs.3.rs-823211/v1

License: (c) (1) This work is licensed under a Creative Commons Attribution 4.0 International License.

Read Full License 


\section{Abstract}

Background: Toxoplasmosis caused by infecting with Toxplasma gondii is a kind of parasitic disease that prevalent all over the world and does great harm to pregnant women and newborns. Effective, rapid and accurate diagnosis $T$. gondii is urgently needed to prevent and treatment the toxoplasmosis. The purpose of this study was to develop a rapid visual detection assay using recombinase aided amplification (RAA) and lateral flow dipstick (LFD) coupled with CRISPR-Cas13a fluorescence, henceforth RAA-Cas13a-LFD, for detection of T. gondii.

Methods: Targeting 529bp gene of T. gondii, the primers and probes for RAA-Cas13a-LFD assay were designed and screened. The reaction time of RAA-LFD-Cas13a assay was optimized, as well as the sensitivity and specificity was further validated. Finally, the diagnostic performance of $T$. gondii was evaluated using the RAA-Cas13a-LFD assay for clinical blood samples.

Results: The RAA-Cas13a-LFD assay was performed in an incubator block at $37^{\circ} \mathrm{C}$ within $2 \mathrm{~h}$, and the amplicons were visible through LFD for naked eye visualization. The detection limit of the developed RAA-Cas13a-LFD assay was $1 \times 10^{-6} \mathrm{ng} / \mu \mathrm{L}$ with high specificity for $T$. gondii. Compared with qPCR assay, there was a consistent positive rate among the clinical blood samples.

Conclusion: In this study, A rapid and visual RAA-Cas13a-LFD assay was developed. It requires no sophisticated equipment and shows promise for on-site surveillance of T. gondii.

\section{Background}

Toxoplasma gondii is an obligate intracellular protozoan parasite that causes toxoplasmosis and threatens warm blooded animal and human health worldwide [1]. It is estimated that more than $30 \%$ of the global population is reportedly seropositive with $T$. gondii, although the infection rates vary significantly by geographical region [2]. A recent analysis reported antibody positive rates of 8.20 and $8.60 \%$ for $T$. gondii in the general population and pregnant women across China, respectively [3]. People with normal immune function may not have typical symptoms and show recessive infection after infection with $T$. gondii, but pregnant women infected with $T$. gondii can lead to premature delivery, abortion, teratosis, stillbirth, etc., and newborn is regularly accompanied by serious eye diseases [1, 4]. For humans with weakened immune function or immunodeficiency, such as AIDS patients, organ transplant recipients, tumor patients, etc., infection with $T$. gondii can cause extreme encephalitis and even death [5, 6]. Therefore, effective, rapid and accurate diagnosis is needed to improve development of treatment approaches, enhance prognosis and control dissemination.

At present, the testing targets for Toxoplasmosis consist of the pathogenic methods, immunological techniques and molecular biological methods $[7,8]$. Above all, direct pathogenic diagnosis of $T$. gondii involves the detection of tachyzoites or tissue cysts by direct microscopy or isolation in cell culture. However, pathologic tissue examination or strain isolation are mostly used for diagnosis of animal infection, less frequently for that of human toxoplasmosis [1]. Currently, nucleic acid and specific 
antibody assays of $T$. gondii are the most commonly used techniques in clinical settings [9]. Particularly, the serum IgM/lgG antibody test has been widely used as a primary screening method for toxoplasmosis infection. However, the sensitivity and specificity of this method are not very high, and it is easy to produce false positive. In recent years, PCR, nested PCR, and real-time PCR (qPCR) assays have become essential tools for the molecular diagnosis of $T$. gondii. These PCR-based amplification techniques have revealed good sensitivity and specificity, and QPCR with probe hybridization reported to be the most sensitive assay [10]. Nevertheless, widespread clinical application of these techniques has been limited by several factors, including the need for sophisticated instruments, complicated operation and well trained personnel.

To date, several new molecular biological methods that require a uniform incubation temperature have been described, which significantly reduce the reaction time and complexity of nucleic acid amplifications. These isothermal nucleic acid amplification methods, such as the loop-mediated isothermal amplification (LAMP), require only a heating block can maintain a constant temperature rather than an expensive thermocycler [11]. However, the LAMP method is prone to aerosol pollution and the result becomes a false positive. Recombinase aid amplification (RAA) is a new technology for nucleic acid amplification, and it works using four enzymes (UvsX, UvsY, SSB, and polymerase) at a constant temperature [12]. The RAA requires only a simple thermostatic device (constant temperature $37-42^{\circ} \mathrm{C}$ ) and a short reaction time (30 $\mathrm{min}$ ) [13]. DNA amplification can be detected by agarose electrophoresis (AGE), real-time fluorescence methods and lateral flow dipstick (LFD) [14], which have subsequently improved the sensitivity and specificity of the RAA assay. Among these optimizations, the LFD method is easy to use and its results easily interpretable. It can be used to detect proteins and nucleic acids [15]. Up to now, RAA-LFD has been applied for detection of microbes, such as Newcastle disease virus [16], dengue virus [13], avian infectious laryngotracheitis virus [17], Novel Coronavirus [18], even to identify the genetic sex of Cynoglossus semilaevis [14]. CRISPR-Cas systems are widely used for genome editing, in recent years, the trans-cleavage activity of Cas proteins has been discovered $[19,20]$. Detection methods based on CRISPR-Cas, which is now also considered a next-generation pathogen detection method, have become established [21, 22]. DNA endonuclease targeted CRISPR trans-reporter and one-hour low-cost multipurpose highly efficient system can detect DNA sequences with high sensitivity and well specificity using CRISPR-Cas13a [23]. Methods such as SHERLOCK (specific high-sensitivity enzymatic reporter unlocking), which typically use target amplification followed by CRISPR-mediated nucleic acid detection have been used to detect SARS-CoV-2 [24].

During toxoplasmosis diagnosis, a series of nucleic acid amplification assays, targeting B1 gene or $529 \mathrm{bp}$ repeat sequences, internal transcriptional spacer sequences (ITS-1), as well as 18S rDNA sequences, have been established. While the $529 \mathrm{bp}$ repeat sequences showed better sensitivity and specificity for the diagnosis of toxoplasmosis [25]. According to literature available, there is no RAA amplification and LFD detection coupled with CRISPR-Cas13a fluorescence assay was been used for the diagnose of toxoplasmosis. In this study, we targeted the 529bp repeated element of $T$. gondii and designed the crRNA probe with the Cas13a-based detection system in combination with RAA and LFD 
methodology for easy visualization. Furthermore, we validated the established RAA-Cas13a-LFD assay by detecting $T$. gondii in genomic DNA extracted from clinical blood samples.

\section{Materials And Methods}

\section{Strains and Clinical samples}

T. gondii tachyzoites (RH strain), preserved at our laboratory, were aseptically cultured in vitro, by serial passages in Vero cells, as previously described [26]. A total of 267 blood samples from patients clinically at the First Affiliated Hospital of Wannan Medical College were collected between December 2018 to November 2020. The blood samples were divided in two aliquots and placed in the anticoagulant tubes (containing $10 \mu \mathrm{L} 0.5 \mu \mathrm{mol} / \mathrm{L}$ EDTA) and non-anticoagulant tubes, respectively. The blood in the nonanticoagulant tubes was centrifuged and the serum was aseptically separated for serology with electrochemiluminescence (ECL) assay (Roche, Switzerland). Blood from anticoagulant tubes is used to extract genomic DNA.

\section{DNA extraction}

A DNeasy Blood \& Tissue Kit (Tiangen Biotech Beijing Co., Ltd., China) was used, to extract genomic DNA from blood samples under the the manufacturer's instructions. All these DNA samples were stored at $-20^{\circ} \mathrm{C}$ until subsequent analysis. Due to the suspected low amount of circulating DNA in these blood samples whose status infection was unknown, each sample was divided into three parts and repeated eluted in order to improve DNA yield and detection rate. Each repliate was then tested and a positive result for any of the sections indicated that the sample was positive.

\section{Construction of standard recombinant plasmids}

Previous studies have reported the 529bp repeated element (GenBank AF146527) as the potential optimal targets for $T$. gondii [27]. The 529bp repeated element is a recently discovered target gene, with up to 300 copies, which offers more sensitivity and specificity during detection [27]. PCR products of $T$. gondii 529bp fragment were amplified in the positive tachyzoites of $T$. gondii, and electrophoresed, excised, purified, and cloned into the $\mathrm{PMD}^{\mathrm{TM}} 19-\mathrm{T}$ vector (Takara). The positive clones were sequenced directionally (ABI 3730). The positive recombinant plasmids of $T$. gondii are kept in our laboratory (Wannan Medical College, China). It is the recombinant plasmids used as standard nucleic acids were quantified with a NanoDrop ND1000 spectrophotometer. Then the recombinant plasmids were prepared with a dilution range $1 \mathrm{ng} / \mu \mathrm{L}-1 \times 10^{-9} \mathrm{ng} / \mu \mathrm{L}$ as a standard control and stored at $-20^{\circ} \mathrm{C}$ until needed.

\section{Design of primer and crRNA probe}

Since success of RAA amplification depends on designing the ideal primers for target the gene, we employed the online primer designing software and designed 5 pairs of specific oligonucleotide primers targeting the $529 \mathrm{bp}$ repeated element of $T$. gondii. The primers annealing temperature are $54-67^{\circ} \mathrm{C}$ with the length about $30-35 \mathrm{bp}$, and the amplicon size is (100-300bp) (Table 1). Specific crRNA probes were 
designed target the specific primer sequence fragment (Table 1). The DNA probes were prepared into RNA by in vitro transcription, according to the HiScribe T7 Quick High Yield RNA Synthesis Kit (New England Biolabs, America). There should be paid to the 5 ' end accessory T7 RNA polymerase promoter sequence during probe design. The transcript (crRNA probe) was purified using RNAXP magnetic beads and the concentration of the product was determined by Qbuit nucleic acid concentration detector (Thermo, America). All primers were synthesized by TsingKe Biotech (Beijing TsingKe Biotechnology, Beijing, China). 
Table 1

Primer sequence for RAA-Cas13a-LFD assay.

\begin{tabular}{|c|c|c|c|}
\hline Primer & Sequence(5'to3') & $\begin{array}{l}\text { Amplicon } \\
\text { sizes } \\
\text { (bp) }\end{array}$ & Description \\
\hline TOX-F1 & ACTACAGACGCGATGCCGCTCCTCC & 283 & \multirow{10}{*}{$\begin{array}{l}\text { Candidates for RAA } \\
\text { primers that were screened } \\
\text { in } \\
\text { this study. TOX-F1/TOX-R1 } \\
\text { pair was used for follow-up } \\
\text { experiment experiments }\end{array}$} \\
\hline TOX-R1 & \multicolumn{2}{|l|}{ TGTCTCCСTCGСССТСТTСTССАСТ } & \\
\hline TOX-F2 & ACACCGGAATGCGATCCAGACGAGA & 126 & \\
\hline TOX-R2 & \multicolumn{2}{|l|}{ GTCCAAGCCTCCGACTCTGTCTCCC } & \\
\hline TOX-F3 & ATATCAGGACTGTAGATGAAGGCGAGGGT & 176 & \\
\hline TOX-R3 & \multicolumn{2}{|l|}{ CGTCTCGTCTGGATCGCATTCCGGTGTCT } & \\
\hline TOX-F4 & TAGATGAAGGCGAGGGTGAGGATGAGGGG & 121 & \\
\hline TOX-R4 & \multicolumn{2}{|l|}{ CTCCAGGAAAAGCAGCCAAGCCGGAAACA } & \\
\hline TOX-F5 & AAGATGTTTCCGGCTTGGCTGCTTTTCCTG & 162 & \\
\hline TOX-R5 & \multicolumn{2}{|l|}{ CCGACTCTGTCTCCCTCGСССТСTTCTCCA } & \\
\hline $\begin{array}{l}\text { T7 } \\
\text { promoter }\end{array}$ & \multicolumn{2}{|l|}{ GAAATTAATACGACTCACTATAGGG } & $\begin{array}{l}\text { Promote the transcription } \\
\text { of amplified DNA to RNA in } \\
\text { vitro transcription. }\end{array}$ \\
\hline Probe1 & \multicolumn{2}{|l|}{ CGUCUCGUCUGGAUCGCAUUCCGGUGUC } & \multirow{5}{*}{$\begin{array}{l}\text { Expected sequences of } \\
\text { guide RNA obtained from } \\
\text { in vitro transcription. } \\
\text { Probe } 1 \text { was used for } \\
\text { follow-up experiment } \\
\text { experiments. }\end{array}$} \\
\hline $\begin{array}{l}\text { Probe-2- } \\
\text { 5-a }\end{array}$ & \multicolumn{2}{|l|}{ UUCUCUCCGCCAUCACCACGAGGAAAGC } & \\
\hline $\begin{array}{l}\text { Probe-2- } \\
5-b\end{array}$ & \multicolumn{2}{|l|}{ CAAUUCUCUCCGCCAUCACCACGAGGAA } & \\
\hline $\begin{array}{l}\text { Probe-3- } \\
\text { 4-a }\end{array}$ & \multicolumn{2}{|l|}{ CUCCGACUCUCGUCGCUUCCCAACCACG } & \\
\hline $\begin{array}{l}\text { Probe-3- } \\
4-b\end{array}$ & \multicolumn{2}{|l|}{ CCGACUCUCGUCGCUUCCCAACCACGCC } & \\
\hline $\begin{array}{l}\text { Lateral } \\
\text { flow } \\
\text { reporter }\end{array}$ & \multicolumn{2}{|l|}{ FAM/mArArUrGrGrCmAmArArUrGrGrCmA/Bio } & $\begin{array}{l}\text { Trans cleavage reporter for } \\
\text { Cas } 13 a\end{array}$ \\
\hline
\end{tabular}

\section{Establishment of RAA assay}

The basic RAA reactions were achieved by the Basic RAA kits (Anhui Microanaly Genetech, Hefei, China). The reaction buffer was premixed according to the following formula: $25 \mu \mathrm{L}$ of rehydration buffer, upstream primers $(10 \mu \mathrm{mol} / \mathrm{L}) 2 \mu \mathrm{L}$, downstream primers $(10 \mu \mathrm{mol} / \mathrm{L}) 2 \mu \mathrm{L}, 25 \times$ SYBR Green $\otimes 1 \mu \mathrm{L}$, 
recombinant plasmids $(1 \mathrm{ng} / \mu \mathrm{L}) 2 \mu \mathrm{L}, \mathrm{MgOAc}$ solution $(280 \mathrm{nmol} / \mathrm{L}) 2.5 \mu \mathrm{L}$, and $17.5 \mu \mathrm{L}$ of nuclease-free water. The aforementioned reaction tube was put into fluorescent quantitative PCR instrument to amplify for $40 \mathrm{~min}$ at $37^{\circ} \mathrm{C}$. The amplified products were analyzed Qsep100 biological analyzer (BIOptic, Taiwan) by collecting the fluorescence.

\section{Establishment of RAA-Cas13a-LFD assay}

Here, targeted detection was used gene editing technology based on nucleic acid amplification and Cas13a-mediated collateral cleavage of a reporter RNA, allowing for real-time detection of the target. The $529 \mathrm{bp}$ target gene of $T$. gondii was amplified by RAA, T7 RNA polymerase transcription of amplified DNA to RNA and detection of target RNA by Cas13a collateral RNA cleavage mediated release of reporter signal. The fluorescence reporter signal can be detected by LFD, LFD is an endpoint assay, with lateral flow strips exposed to the reaction mixture post incubation (Fig. 1).

The RAA-Cas13a-LFD reaction formula was as the following: LwCas13a nuclease ( $45 \mathrm{nmol} / \mathrm{L}$ ) (Anhui Microanaly Genetech, Hefei, China)), Lateral flow reporter molecule (125nmol/L) (Integrated DNA Technologies, lowa, USA), RNase inhibitor (1 $\mu \mathrm{L})$ (New England Biolabs, America), ATP (1mM), GTP $(1 \mathrm{mM})$, UTP $(1 \mathrm{mM})$, CTP $(1 \mathrm{mM})$ and T7 polymerase $(0.6 \mu \mathrm{L})$ were mixed to the total system $8 \mu \mathrm{L}$. Then, $1 \mu \mathrm{L}$ crRNA probe $(30 \mathrm{ng} / \mu \mathrm{L})$ and $1 \mu \mathrm{L}$ of RAA products were added into $8 \mu \mathrm{L}$ of aforementioned mixture and mixed thoroughly. It is recommended to incubation at $37^{\circ} \mathrm{C}$ for 40 minutes. Add $20 \mu \mathrm{L}$ diluent buffer to the $10 \mu \mathrm{L}$ of the reaction and mix well. The lateral-flow dipsticks were insert into the mixture for 3-5 minutes. and results were recorded until the positive control line was visualized.

\section{Results explanation of RAA-Cas13a-LFD assay}

Cas13a detection was adapted for lateral flow detection (LFD), with an important alteration: the Lateral flow reporter was replaced with FAM-ssRNA-Biotin reporter (FB reporter) $[28,29]$. Without trans cleavage, the FB reporter will remain intact and its biotinylated end can be captured by streptavidin at the control line. Anti-FAM antibody conjugated to gold nanoparticles can then bind the exposed FAM moiety, resulting in the color deposit on the control line. It was negative if only control line (red band) appeared, indicating that there is not the amplification fragment of the target gene in the sample (Fig. 2). On the other hand, if the FB reporter has undergone trans cleavage by Cas13a, a portion of reporter molecules will contain biotin, but not FAM. As a result, fewer FAM ends will be present at the control line, and a higher amount of antibody-conjugated gold nanoparticles will be able to travel further to deposit on the test line. It was positive when test line and control line both appeared or only test line red band appears, indicating that the target gene of $T$. gondii to be detected in the sample.

\section{Evaluation of RAA-Cas13a-LFD specificity and sensitivity}

In order to determine the analytical specificity of the RAA-Cas13a-LFD assay developed in this study, the nucleic acids of human blood, Ascaris lumbricoides, Digramma interrupta, Entamoeba coli, Fasciola gigantica, Plasmodium vivax, Schistosoma japonicum, Taenia solium and Trichinella spiralis were used 
as templates for the RAA reactions. The sensitivity of the RAA-Cas13a-LFD assay was assessed using 10fold serial dilutions of the recombinant plasmids ranging from $1 \mathrm{ng} / \mu \mathrm{L}-1 \times 10^{-9} \mathrm{ng} / \mu \mathrm{L}$. All experiments were carried out in duplicate, and the recombinant plasmid was the positive control and $\mathrm{dd}_{2} \mathrm{O}$ was the negative control. Different RAA products were directly analyzed by lateral-flow dipsticks.

To verify the analytical specificity and sensitivity of the RAA-Cas13a-LFD assay developed in this study, a real-time PCR (qPCR) also performed using the forward primer, reverse primer, and probe primer target the the same $529 \mathrm{bp}$ gene. The sequence of forward primer, reverse primer, and probe primer are AGACGAGACGACGCTTTCC, GCATCTGGATTCCTCTCCTACC, and CGTCCAAGCCTCCGACTCTGTCTC, respectivly. qPCR reactions were performed in $20 \mu \mathrm{L}$ reaction volumes, comprising $10 \mu \mathrm{L} 2 \times$ Master Mix (Roche, Switzerland), $10 \mu \mathrm{M}$ of each forward and reverse primers, $10 \mu \mathrm{M}$ of probe primer, and $2 \mu \mathrm{L}$ of the template. Amplification was performed as follows: initial denaturation at $95^{\circ} \mathrm{C}$ for $30 \mathrm{~s}$; followed by 40 cycles of denaturation at $95^{\circ} \mathrm{C}$ for $10 \mathrm{~s}$, primer annealing at $60^{\circ} \mathrm{C}$ for $30 \mathrm{~s}$; dissociation at $95^{\circ} \mathrm{C}$ for $15 \mathrm{~s}$, $60^{\circ} \mathrm{C}$ for $60 \mathrm{~s}$, and $95^{\circ} \mathrm{C}$ for $15 \mathrm{~s}$. The products of qPCR were visualized according to amplification curve generated by the LightCycler 96 qPCR instrument (Roche, Switzerland).

\section{Application of the RAA-Cas13a-LFD assay for clinical samples}

We tested the established RAA-Cas13a-LFD method for detection of $T$. gondii in blood samples collected from patients of Clinical Laboratory. A total of 267 blood samples were simultaneously tested with serology ECL assay, qPCR and the RAA-Cas13a-LFD assay for detection of $T$. gondii. To evaluate the validity of establishment RAA-Cas13a-LFD assay, blood samples were all to amplify the 529 gene for detection of $T$. gondii by qPCR assay.

\section{Results}

\section{Optimization of RAA primers}

There are five pairs of primers were designed for $529 \mathrm{bp}$ gene region in accordance with the requirements of RAA nucleic acid amplification (Table 1). After the products were amplified by RAA nucleic acid amplification at $37^{\circ} \mathrm{C}$ for 40 minutes, they were screened by fluorescence detection and capillary electrophoresis.

According to the primers melting curves (Fig. 3), the primer pairs of 1 and 3 have a single high peak, and there is no nonspecific amplification. The size of amplified product fragment of primer pair 1 and 3 are about $283 \mathrm{bp}$ and $176 \mathrm{bp}$, respectively, they are consistent with the expected target fragment; Furthermore more, the total amount of products of primer pair 1 and 3 are relatively high (Fig. $4 a$ and 4c, Table 2). The primer pairs of 2 and 5 have many impurity peaks in the melting curve, resulting in nonspecific amplification and have a low total amount of amplified products (Fig. 3, Fig. 4b and 4e, Table 2). Although the primer dissolution curve of primer 4 is a single peak, and there are no nonspecific amplification. While the total amount of product is low, indicating poor amplification efficiency (Fig. 3 , Fig. 4d, Table 2). In brief, based on the results of the melting curve and the peak of the amplified product, 
the amplification efficiency of primer pairs of 1 and 3 is relative better. Hence, the primer pairs of 1 and 3 were used in the follow up probe optimizing test.

Table 2

Amplification products of 5 pairs of primers by Qsep100 bioanalyzer test

\begin{tabular}{|lllll|}
\hline $\begin{array}{l}\text { Primer } \\
\text { pair }\end{array}$ & $\begin{array}{l}\text { Size of main } \\
\text { peak (bp) }\end{array}$ & $\begin{array}{l}\text { Total amount of } \\
\text { target product(ng) }\end{array}$ & $\begin{array}{l}\text { Total amount of nonspecific } \\
\text { amplification products(ng) }\end{array}$ & $\begin{array}{l}\text { Target } \\
\text { product } \\
\text { ratio(\%) }\end{array}$ \\
\hline $\begin{array}{l}\text { Primer } \\
\text { pair 1 }\end{array}$ & 283 & 990 & 0 & 100 \\
\hline $\begin{array}{l}\text { Primer } \\
\text { pair 2 }\end{array}$ & 126 & 72 & 90 & 44 \\
\hline $\begin{array}{l}\text { Primer } \\
\text { pair 3 }\end{array}$ & 176 & 560 & 0 & 100 \\
\hline $\begin{array}{l}\text { Primer } \\
\text { pair 4 }\end{array}$ & 121 & 150 & 0 & 100 \\
\hline $\begin{array}{l}\text { Primer } \\
\text { pair 5 }\end{array}$ & 162 & 160 & 164 & 49 \\
\hline
\end{tabular}

\section{Optimization of crRNA probe primers}

After the positive plasmid is amplified by RAA isothermally, fluorescence method is used to optimize the combination of primer and probe. The amplification efficiency of the primer-probe combination was evaluated by the fluorescence amplification curve. According to the fluorescence amplification curve (Fig. $5 a)$, the fluorescence value of positive plasmid group based on the Primer1 + Probe 1 combination has a significant difference in compared with the negative control (NTC) group, indicating that the detection result is positive and the amplification efficiency is well; while there are significant amplification based on the Primer1 + Probe3-4-a and Primer3 + Probe3-4-a combination and the consistency is poor (Fig. 5b); similar results, the amplification curve of the Primer1 + Probe3-4-b has poor consistency, and the fluorescence value of Primer3 + Probe3-4-b has no significant difference compared with the NTC group, the amplification efficiency is extremely lower (Fig. 5c). In summary, the Primer $1+$ Probe 1 combination has the best amplification efficiency, which was used in the subsequent RAA-Cas13a-LFD experiments.

\section{Optimization of the RAA-Cas13a-LFD assay conditions}

The preferred time for the RAA-Cas13a-LFD reaction were evaluated. First, RAA basic reactions were carried out at $37^{\circ} \mathrm{C}$ for 40 minutes in a heating block. Results of the amplification showed that the target DNA could be successfully amplified. A body temperature of $37^{\circ} \mathrm{C}$ was chosen as the optimal RAACas13a-LFD temperature. Take the plasmids with concentrations of $1 \times 10^{-5} \mathrm{ng} / \mu \mathrm{L}, 1 \times 10^{-6} \mathrm{ng} / \mu \mathrm{L}$ and $1 \times 10^{-7} \mathrm{ng} / \mu \mathrm{L}$ as templates; the amplification times are $20 \mathrm{~min}, 30 \mathrm{~min}$ and $40 \mathrm{~min}$ for the reaction. The results showed that when the RAA-Cas13a-LFD reaction was amplified for 20 minutes, the detection limit 
of plasmid concentrations was $1 \times 10^{-5} \mathrm{ng} / \mu \mathrm{L}$, and when the RAA-Cas13a-LFD reaction was amplified for 30 minutes and 40 minutes, the detection limit of plasmid concentrations was $1 \times 10^{-6} \mathrm{ng} / \mu \mathrm{L}$ (Fig. 6). The detection limit of amplification yielded did not change with the increase of time from $30 \mathrm{~min}$ to $40 \mathrm{~min}$, so 30 minutes was chosen as the RAA-Cas13a-LFD reaction time in this study.

\section{Sensitivity of the established RAA-Cas13a-LFD assay}

The sensitivity of the RAA-Cas13a-LFD assay was determined by using serial 10 -fold dilutions of a positive control template (positive recombinant plasmid of $T$. gondii). These dilutions ranged were from 1 $\mathrm{ng} / \mu \mathrm{L}$ to $1 \times 10^{-9} \mathrm{ng} / \mu \mathrm{L}$, with $\mathrm{ddH}_{2} \mathrm{O}$ included as a negative control. The amplified reaction was performed for $30 \mathrm{~min}$, and the lowest detection concentration of RAA-Cas13a-LFD method was determined. As shown in Fig. 7a, there were the corresponding visible test lines when the concentration of recombinant plasmids was $>1 \times 10^{-6} \mathrm{ng} / \mu \mathrm{L}$. We also performed a qPCR as described before. It can be seen that the minimum detection limit of the $\mathrm{qPCR}$ is $1 \times 10^{-8} \mathrm{ng} / \mu \mathrm{L}$ (Fig. 7B). The results indicated that the limit of RAA-Cas13a-LFD assay for T. gondii is slightly less sensitive compared with qPCR in the level of detection limit.

\section{Specificity of the established RAA-Cas13a-LFD assay}

We tested specificity of RAA-Cas13a-LFD and qPCR methods using genomic DNA samples from human blood, Ascaris lumbricoides, Digramma interrupta, Entamoeba coli, Fasciola gigantica, Plasmodium vivax, Schistosoma japonicum, Taenia solium and Trichinella spiralis. The T. gondii positive plasmid was used as a positive control, and $\mathrm{dd}_{2} \mathrm{O}$ was used as a negative control. Only $T$. gondii positive plasmids showed amplification using both methods, and produced visible test bands (RAA-Cas13a-LFD) and amplification curves (qPCR). While the other DNA templates showed no signals (Fig. 8), demonstrating that the established RAA-Cas13a-LFD method has good specificity.

\section{Clinical performance of the established RAA-Cas13a-LFD assay}

To evaluate the clinical performance of the T. gondii RAA-Cas13a-LFD assay, a total of 267 clinical blood samples (137 males and 130 females) were collected from patients of Laboratory Medicine and tested using ECL, qPCR and the established RAA-Cas13a-LFD methods, respectively. The results showed that the positive rates of $T$. gondii in the blood samples are various in different methods (Table 3 ). Higher positive rates were detected by RAA-Cas13a-LFD $(1.50 \%, 4 / 267)$ than by ECL-IgM $(1.12 \%, 3 / 267)$. Compared with qPCR, there was a consistent positive rate between qPCR and RAA-Cas13a-LFD assays (Fig. 9, Table 3). Indicating that the established RAA-Cas13a-LFD assay offers excellent performance for detecting $T$. gondii as the same as qPCR in clinical setting. 
Table 3

Comparation of ECL, qPCR and RAA-Cas13a-LFD

assay for detection of T. gondii in blood samples

\begin{tabular}{|lll|}
\hline \multirow{2}{*}{ Test methods } & \multicolumn{2}{l|}{ Blood samples $(\mathbf{n}=267)$} \\
\cline { 2 - 3 } & positive & negative \\
\hline ECL IgG & $34(12.73 \%)$ & $233(87.27 \%)$ \\
\hline IgM & $3(1.12 \%)$ & $264(98.88 \%)$ \\
\hline qPCR & $4(1.50 \%)$ & $263(98.50 \%)$ \\
\hline RAA-Cas13a-LFD & $4(1.50 \%)$ & $263(98.50 \%)$ \\
\hline
\end{tabular}

\section{Discussion}

Thus far, several nucleic acid-based detection platforms have been developed for $T$. gondii, including traditional PCR, nested PCR, qPCR and LAMP coupled with LFD. Although these methods offer good sensitivity, they are limited by various constraints such as susceptibility to false positives and lack of compatibility with point-of-need applications [7]. LAMP is characterized by a streamlined protocol and exemplary detection limit of 1 copy of $T$. gondii DNA per reaction, but spurious amplification can occasionally arise and is prone to aerosol pollution [5]. RAA-LFD is to perform isothermal amplification of the target gene or specimen by the RAA method and then combine with LFD technology, LFD is a technology that finally realizes the visual analysis of amplified products. This technology does not require expensive equipment, can quickly and effectively amplify the target fragment under constant temperature conditions, and the result of the reaction can be judged by the naked eye. Whereas RAA alone was not sensitive enough to detect low levels of target [23]. In multiple Cas family members, including Cas13, Cas12 and Cas14 effector, cutting the target nucleic acid can trigger the cleavage of irrelevant single-strand DNA (ssDNA) or single-strand RNA (ssRNA). This collateral cleavage has been exploited for nucleic acid detection [30-32]. CRISPR-Cas13a (formerly C2c2), a Type VI Class 2 CRISPRCas effector, is a single-component enzyme targeting single-stranded RNA with a guide RNA. Binding with a complementary ssRNA will activate its targeting and general ssRNase activity [19, 23], the latter responsible for collateral ssRNA cleavage. In the specific high-sensitivity enzymatic reporter unlocking (SHERLOCK) platform, quenched fluorophore is added to the collateral substrate, Cas13a system cleaves a nucleic acid reporter and generates a detectable signal, thus enabling target RNA detection [28]. The fluorescence signal is monitored using the spectroscopy reader, such as LDF. The CRISPR-Cas13a system has been employed for nucleic acid detection of a variety of pathogens, including SARS-CoV-2, Zika virus, dengue virus, among others [23].

Therefore, for nucleic acid detection of $T$. gondii in this study, a RAA is used to amplify target DNA, which is then transcribed by T7 RNA polymerase promoter into RNA for subsequent LwCas13a detection, then the fluorescence signal is monitored by LFD observation with naked eyes. A new type of RAA-LFD combined Cas13a detection method for T. gondii based on 529 bp gene was successfully established. It 
had no cross-reactivity with other parasites and could consistently detect $1 \times 10^{-6} \mathrm{ng} / \mu \mathrm{L}$ of DNA per reaction. The established RAA-Cas13a-LFD assay can complete the amplification reaction at a constant temperature of $37^{\circ} \mathrm{C}$ for less than 2 hours for naked eye visualization.

With the detection limit of $1 \times 10^{-6} \mathrm{ng} / \mu \mathrm{L}$ per reaction, the sensitivity of RAA-Cas $13 a-L F D$ assay is slightly less sensitive than qPCR, which could explain the disagreement between two approaches at the lowest target concentration of $T$. gondii [33]. In addition, qPCR and RAA-Cas13a-LFD are suitable for different environmental and laboratory conditions to detection of $T$. gondii. These advantages combined render RAA-Cas13a-LFD a strong option for routine surveillance in resource-limited settings. Nonetheless, RAALFD combined Cas13a assay developed in this work should still be sensitive enough to permit timely detection of $T$. gondii among the clinical samples; the positive rate of RAA-Cas13a-LFD was consistent with that of qPCR among the clinical samples. It was found that qPCR and RAA-Cas13a-LFD methods were all detected 4 positive cases of 267 clinical samples, while ELISA method $\left(\operatorname{lgM}^{+}\right)$only detected 3 cases of positive specimens. The assay established in this study indicated that the sensitivity of RAACas13a-LFD method is higher than conventional ECL detection.

Through the $T$. gondii can be detected from the clinical blood samples within $2 \mathrm{~h}$ by naked eye observation under a constant temperature heating block in this study, but it is on the premise of the genome DNA from the blood sample has been extracted. The effective acquisition of nucleic acid detection is the basis of simple and fast RAA-Cas13a-LFD assay in the current study. Therefore, further development is needed especially for simply DNA acquisition techniques from blood sample. A rapid and sensitive RAA assay to detect Bordetella pertussis using the DNA obtained by boiling clinical samples of respiratory secretions has been reported [34]. Additionally, compared with traditional PCR technology, CRISPR/ Cas13-based nucleic acid detection technology has higher sensitivity, better specificity, and does not require expensive equipment and professional operators [35]. While compared with qPCR in this study, the detection limit of blood-extracted $T$. gondii DNA RAA-Cas13a-LFD assay should be fully determined through screening of primer and probe combination, to achieve a more similar sensitivity to qPCR.

\section{Conclusions}

In conclusion, the developed RAA-LFD combined Cas13a assay has high specificity and sensitivity, and is visual, rapid and reliable for $T$. gondii detection. A heating instrument cannot be procured; it may even be possible to exploit body heat for incubation in this establishment assay. Furthermore, the assay could be adapted into an LFD format that does not demand any visualization instrument to achieve visual detection of $T$. gondii. It has the advantages of simple operation, fast response, high sensitivity, good specificity, and visualization of reaction results. It is very suitable for on-site testing and has a good prospect in clinical applications.

\section{Declarations}


Acknowledgements

The authors would like to thank Dr. Xiaoning Li for guidance and support in collecting the blood samples from Clinical Laboratory and his special enthusiasm with this study.

\section{Authors' contributions}

JZ and FF conceived and designed the experiments; JZ, FF, QX, ZZ and MZ performed the work and acquired the data. JZ and YL wrote the manuscript. QX provided methodological input, and contributed to writing the manuscript. All authors read and approved the final manuscript.

\section{Funding}

This work was supported by grants of Academic Aid Program for top-notch talents in provincial universities (gxbjZD2020071), Key Program in the Youth Elite Support Plan in Universities of Anhui Province (gxyqZD2016171) and Anhui Province Key Laboratory of active biological macro-molecules.

\section{Availability of data and materials}

All data generated or analyzed during this study are included in this published article

\section{Ethics approval and consent to participate}

All aspects of the study were performed in accordance with national ethics regulations and approved by the Medical Ethics Committee of Wannan Medical College.

\section{Consent for publication}

Not applicable.

\section{Competing interests}

The authors declare that they have no competing interests.

\section{References}

1. Xue Y, Kong Q, Ding H, Xie C, Zheng B, Zhuo X, Ding J, Tong Q, Lou D, Lu S et al: A novel loopmediated isothermal amplification-lateral-flow-dipstick (LAMP-LFD) device for rapid detection of Toxoplasma gondii in the blood of stray cats and dogs. Parasite 2021, 28:41.

2. Thangarajah P, Hajissa K, Wong WK, Abdullah MA, Ismail N, Mohamed Z: Usefulness of paired samples for the Serodiagnosis of toxoplasmosis infection in a tertiary teaching Hospital in Malaysia. BMC infectious diseases 2019, 19(1):202.

3. Ji-Long S, Li Y: [Prevalence and fundamental researches of prevention and treatment of toxoplasmosis in China: an overview]. Zhongguo xue xi chong bing fang zhi za zhi = Chinese journal 
of schistosomiasis control 2019, 31(1):71-76.

4. Clough B, Frickel EM: The Toxoplasma Parasitophorous Vacuole: An Evolving Host-Parasite Frontier. Trends in parasitology 2017, 33(6):473-488.

5. Zhao XY, Ewald SE: The molecular biology and immune control of chronic Toxoplasma gondii infection. The Journal of clinical investigation 2020, 130(7):3370-3380.

6. Lima TS, Lodoen MB: Mechanisms of Human Innate Immune Evasion by Toxoplasma gondii. Frontiers in cellular and infection microbiology 2019, 9:103.

7. Li R, Ma Y, Li J, Zhou P, Zheng F, Liu Q, Gao W: Application of Toxoplasma gondii GRA15 peptides in diagnosis and serotyping. Microbial pathogenesis 2020, 143:104168.

8. Zhang K, Lin G, Han Y, Li J: Serological diagnosis of toxoplasmosis and standardization. Clinica chimica acta; international journal of clinical chemistry 2016, 461:83-89.

9. Hegazy MK, Awad SI, Saleh NE, Hegazy MM: Loop mediated isothermal amplification (LAMP) of Toxoplasma DNA from dried blood spots. Experimental parasitology 2020, 211:107869.

10. Rostami A, Karanis P, Fallahi S: Advances in serological, imaging techniques and molecular diagnosis of Toxoplasma gondii infection. Infection 2018, 46(3):303-315.

11. Kolm C, Martzy R, Fuhrer M, Mach RL, Krska R, Baumgartner S, Farnleitner AH, Reischer GH: Detection of a microbial source tracking marker by isothermal helicase-dependent amplification and a nucleic acid lateral-flow strip test. Scientific reports 2019, 9(1):393.

12. Zhang X, Guo L, Ma R, Cong L, Wu Z, Wei Y, Xue S, Zheng W, Tang S: Rapid detection of Salmonella with Recombinase Aided Amplification. Journal of microbiological methods 2017, 139:202-204.

13. Xiong Y, Luo Y, Li H, Wu W, Ruan X, Mu X: Rapid visual detection of dengue virus by combining reverse transcription recombinase-aided amplification with lateral-flow dipstick assay. International journal of infectious diseases : IJID : official publication of the International Society for Infectious Diseases 2020, 95:406-412.

14. Zhao N, Jia L, Che J, He X, Zhang B: Novel molecular marker for RAA-LFD visual detection of Cynoglossus semilaevis sex. Animal reproduction science 2021, 226:106713.

15. Li Y, Yu Z, Jiao S, Liu Y, Ni H, Wang Y: Development of a recombinase-aided amplification assay for rapid and sensitive detection of porcine circovirus 3. Journal of virological methods 2020, 282:113904.

16. Wang W, Wang C, Bai Y, Zhang P, Yao S, Liu J, Zhang T: Establishment of reverse transcription recombinase-aided amplification-lateral-flow dipstick and real-time fluorescence-based reverse transcription recombinase-aided amplification methods for detection of the Newcastle disease virus in chickens. Poultry science 2020, 99(7):3393-3401.

17. Wang W, Wang C, Zhang Z, Zhang P, Zhai X, Li X, Zhang T: Recombinase-aided amplification-lateral flow dipstick assay-a specific and sensitive method for visual detection of avian infectious laryngotracheitis virus. Poultry science 2021, 100(3):100895. 
18. Zheng YZ, Chen JT, Li J, Wu XJ, Wen JZ, Liu XZ, Lin LY, Liang XY, Huang HY, Zha GC et al: Reverse Transcription Recombinase-Aided Amplification Assay With Lateral Flow Dipstick Assay for Rapid Detection of 2019 Novel Coronavirus. Frontiers in cellular and infection microbiology 2021, 11:613304.

19. Abudayyeh OO, Gootenberg JS, Konermann S, Joung J, Slaymaker IM, Cox DB, Shmakov S, Makarova KS, Semenova E, Minakhin L et al: C2c2 is a single-component programmable RNA-guided RNA-targeting CRISPR effector. Science 2016, 353(6299):aaf5573.

20. Broeders M, Herrero-Hernandez P, Ernst MPT, van der Ploeg AT, Pijnappel W: Sharpening the Molecular Scissors: Advances in Gene-Editing Technology. iScience 2020, 23(1):100789.

21. Zhu CS, Liu CY, Qiu XY, Xie SS, Li WY, Zhu L, Zhu LY: Novel nucleic acid detection strategies based on CRISPR-Cas systems: From construction to application. Biotechnology and bioengineering 2020, 117(7):2279-2294.

22. Wang $X$, Shang $X$, Huang $X$ : Next-generation pathogen diagnosis with CRISPR/Cas-based detection methods. Emerging microbes \& infections 2020, 9(1):1682-1691.

23. Gootenberg JS, Abudayyeh 00, Lee JW, Essletzbichler P, Dy AJ, Joung J, Verdine V, Donghia N, Daringer NM, Freije CA et al: Nucleic acid detection with CRISPR-Cas13a/C2c2. Science 2017, 356(6336):438-442.

24. Joung J, Ladha A, Saito M, Kim NG, Woolley AE, Segel M, Barretto RPJ, Ranu A, Macrae RK, Faure $\mathrm{G}$ et al: Detection of SARS-CoV-2 with SHERLOCK One-Pot Testing. The New England journal of medicine 2020, 383(15):1492-1494.

25. Soltani Tehrani B, Mirzajani E, Fallahi S, Manouchehri Naeini K, Mahmoudi MR, Safari Kavishahi M, Eskandari V, Zebardast N: Challenging TaqMan probe-based real-time PCR and loop-mediated isothermal amplification (LAMP): the two sensitive molecular techniques for the detection of toxoplasmosis, a potentially dangerous opportunistic infection in immunocompromised patients. Archives of microbiology 2020, 202(7):1881-1888.

26. Kong QM, Lu SH, Tong QB, Lou D, Chen R, Zheng B, Kumagai T, Wen LY, Ohta N, Zhou XN: Loopmediated isothermal amplification (LAMP): early detection of Toxoplasma gondii infection in mice. Parasites \& vectors 2012, 5:2.

27. Homan WL, Vercammen M, De Braekeleer J, Verschueren H: Identification of a 200- to $\mathbf{3 0 0}$-fold repetitive 529 bp DNA fragment in Toxoplasma gondii, and its use for diagnostic and quantitative PCR. International journal for parasitology 2000, 30(1):69-75.

28. Gootenberg JS, Abudayyeh 00 , Kellner MJ, Joung J, Collins JJ, Zhang F: Multiplexed and portable nucleic acid detection platform with Cas13, Cas12a, and Csm6. Science 2018, 360(6387):439-444.

29. Sullivan TJ, Dhar AK, Cruz-Flores R, Bodnar AG: Rapid, CRISPR-Based, Field-Deployable Detection Of White Spot Syndrome Virus In Shrimp. Scientific reports 2019, 9(1):19702.

30. Chen JS, Ma E, Harrington LB, Da Costa M, Tian X, Palefsky JM, Doudna JA: CRISPR-Cas12a target binding unleashes indiscriminate single-stranded DNase activity. Science 2018, 360(6387):436-439. 
31. Harrington LB, Burstein D, Chen JS, Paez-Espino D, Ma E, Witte IP, Cofsky JC, Kyrpides NC, Banfield JF, Doudna JA: Programmed DNA destruction by miniature CRISPR-Cas14 enzymes. Science 2018, 362(6416):839-842.

32. Li L, Li S, Wu N, Wu J, Wang G, Zhao G, Wang J: HOLMESv2: A CRISPR-Cas12b-Assisted Platform for Nucleic Acid Detection and DNA Methylation Quantitation. ACS synthetic biology 2019, 8(10):22282237.

33. Kanitchinda S, Srisala J, Suebsing R, Prachumwat A, Chaijarasphong T: CRISPR-Cas fluorescent cleavage assay coupled with recombinase polymerase amplification for sensitive and specific detection of Enterocytozoon hepatopenaei. Biotechnology reports 2020, 27:e00485.

34. Zhang RQ, Li GX, Li XN, Shen XX, Gao Y, Wang L, Fan T, Duan QX, Wang YK, Wang J et al: A rapid and sensitive recombinase aided amplification assay incorporating competitive internal control to detect Bordetella pertussis using the DNA obtained by boiling. International journal of infectious diseases : IJID : official publication of the International Society for Infectious Diseases 2019, 86:108-113.

35. Broughton JP, Deng X, Yu G, Fasching CL, Servellita V, Singh J, Miao X, Streithorst JA, Granados A, Sotomayor-Gonzalez A et al: CRISPR-Cas12-based detection of SARS-CoV-2. Nature biotechnology 2020, 38(7):870-874.

\section{Figures}

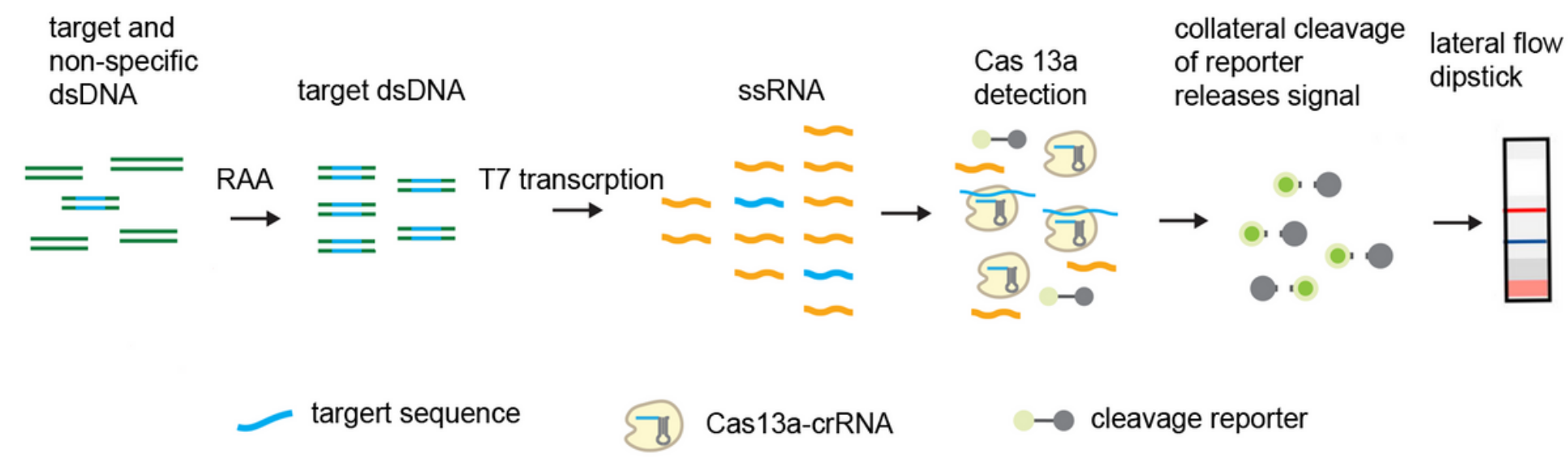

Figure 1

Schematic of T. gondii detection with RAA-Cas13a-LFD assay. Steps include: amplification of target DNA with RAA; T7 RNA polymerase transcription of amplified DNA to RNA; target recognition the target RNA with Cas13a-crRNA, collateral cleavage of fluorophore-quencher reporter (i.e. lateral flow reporter) and release fluorophore signal; visualization of the unleashed fluorescence signal by lateral flow dipstick. 


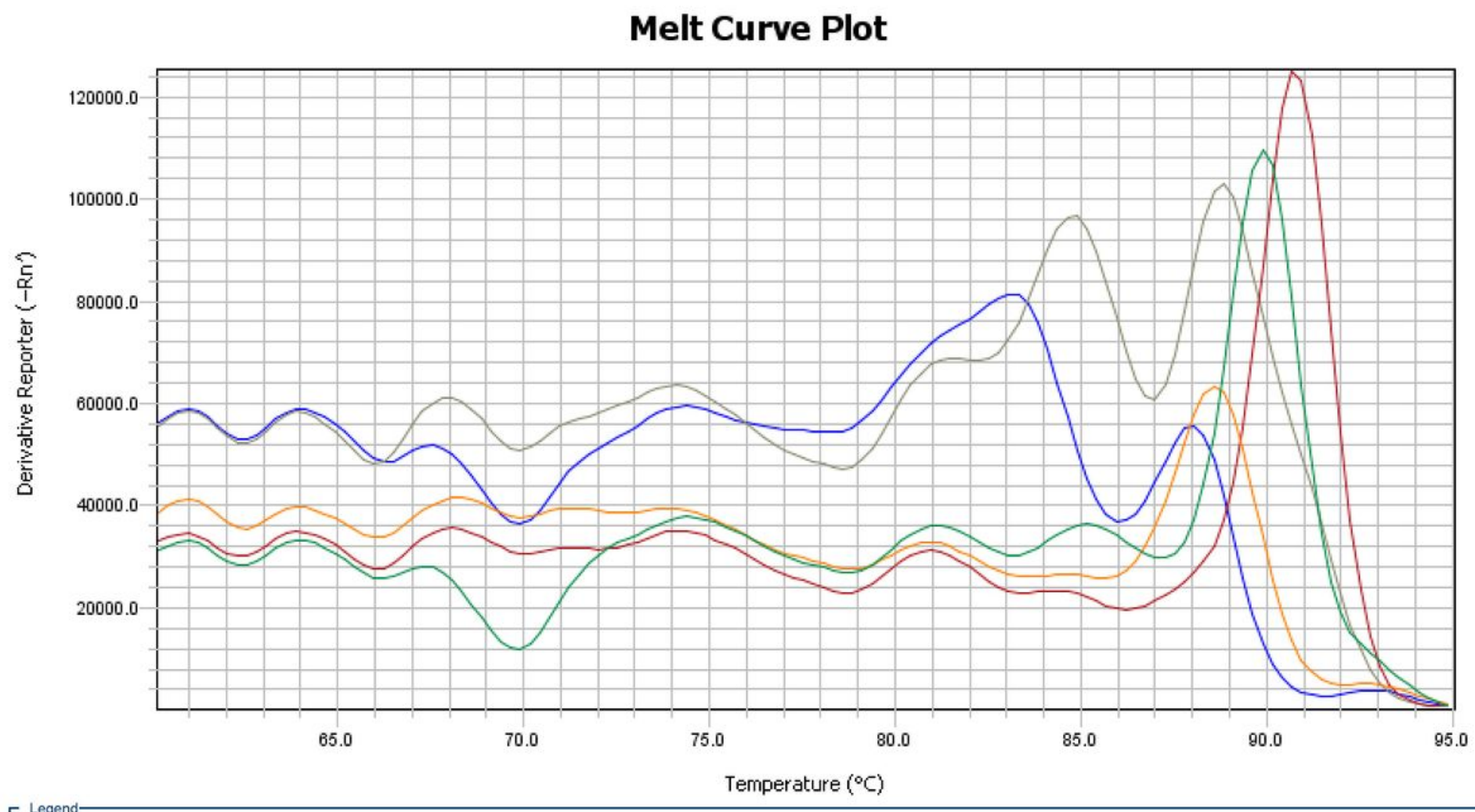

\begin{tabular}{l|l|l|l|l|} 
Primer 1 & Primer 2 & Primer 3 & Primer 4 & Primer 5
\end{tabular}

Figure 2

Results explanation of RAA-Cas13a-LFD assay.

\begin{tabular}{lcc}
\hline Positive result & Negative result & Invalid result \\
\hline & & \\
C and T appear & C appears alone & Neither C nor T appear \\
or T appears alone & \\
\hline
\end{tabular}

Note: $\mathrm{T}$ means test line; $\mathrm{C}$ means control line.

Figure 3

The melting curves of 5 pairs of primers. 
a

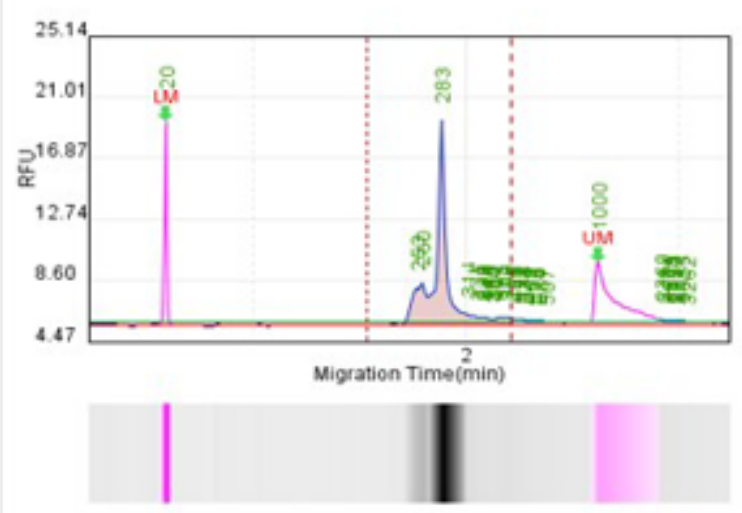

C

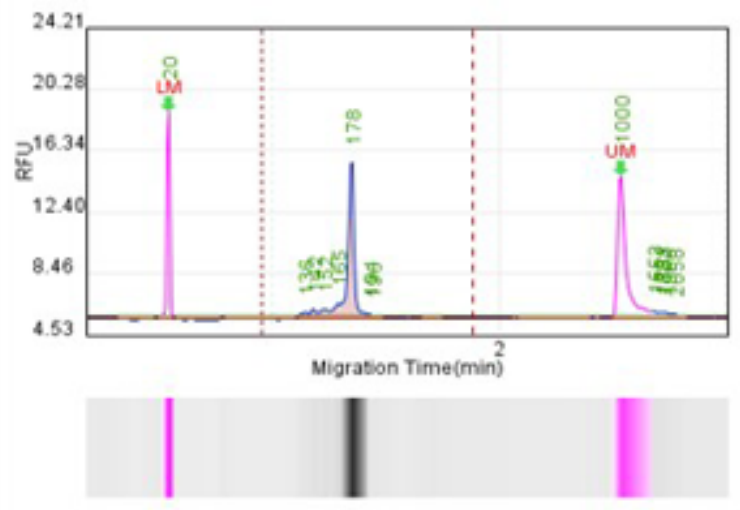

e

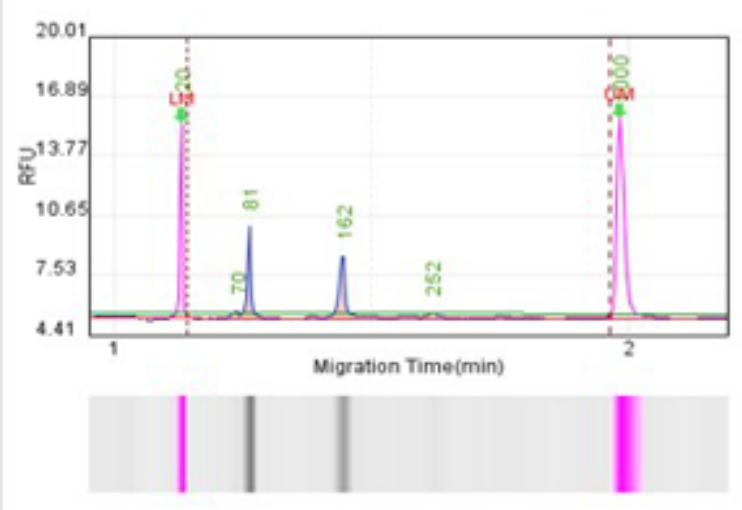

b

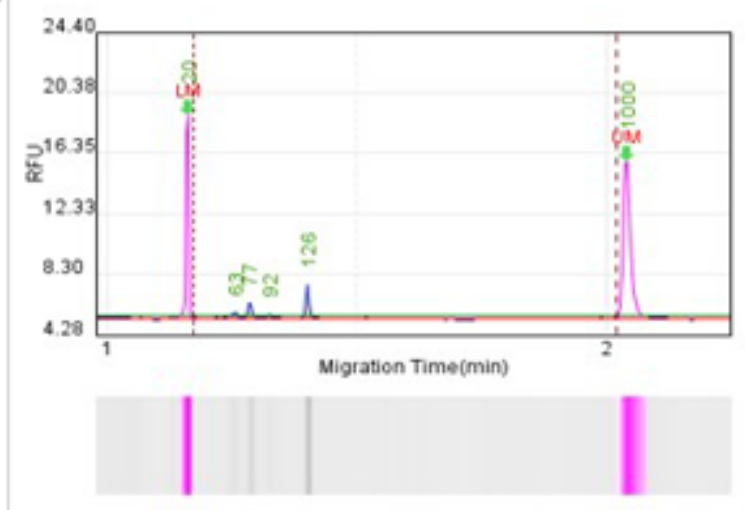

d

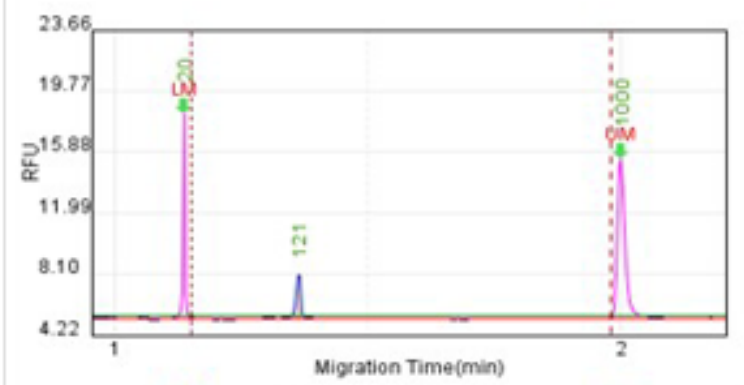

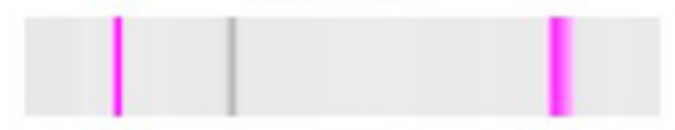

\section{Figure 4}

The peaks of amplified products of 5 pairs of primers. a Primer pair 1. b Primer pair 2. c Primer pair 3. d Primer pair 4. e Primer pair 5. LM and UM represent for Marker, the abscissa represents the band size of the amplified product, the ordinate represents the relative peak value, and the peak area represents the total product. 
a

Amplification Plot

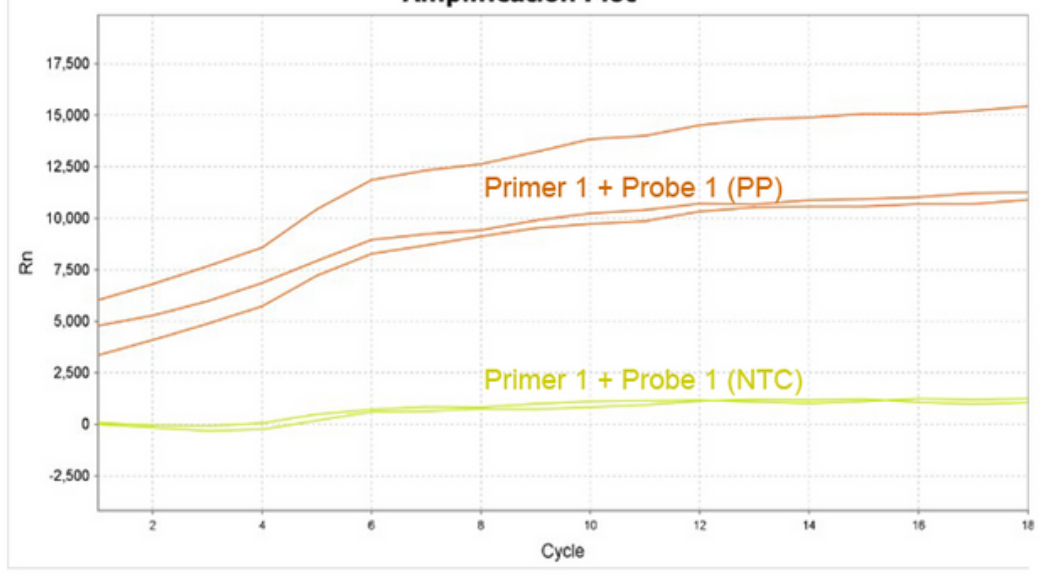

b

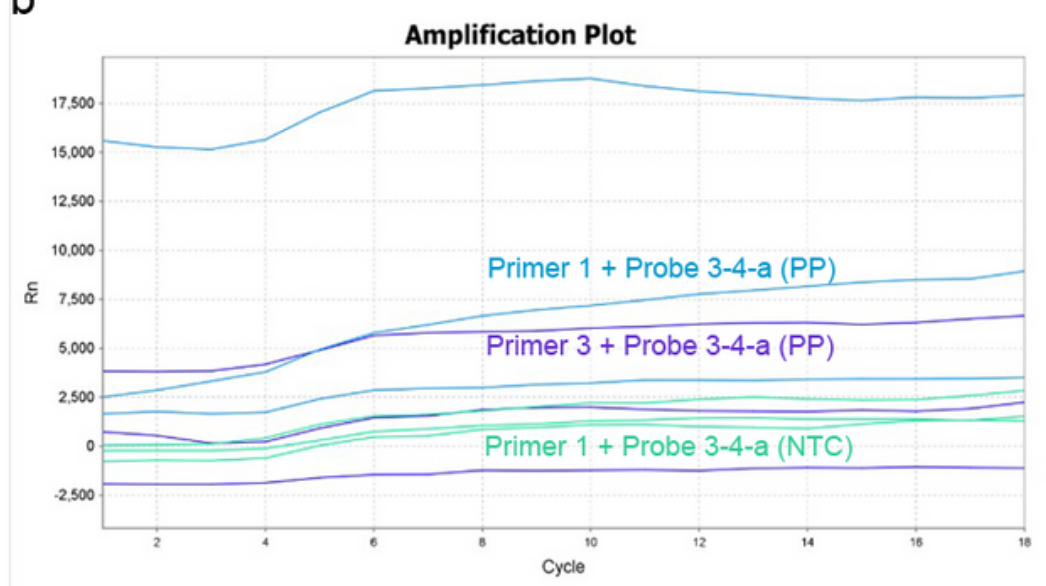

C

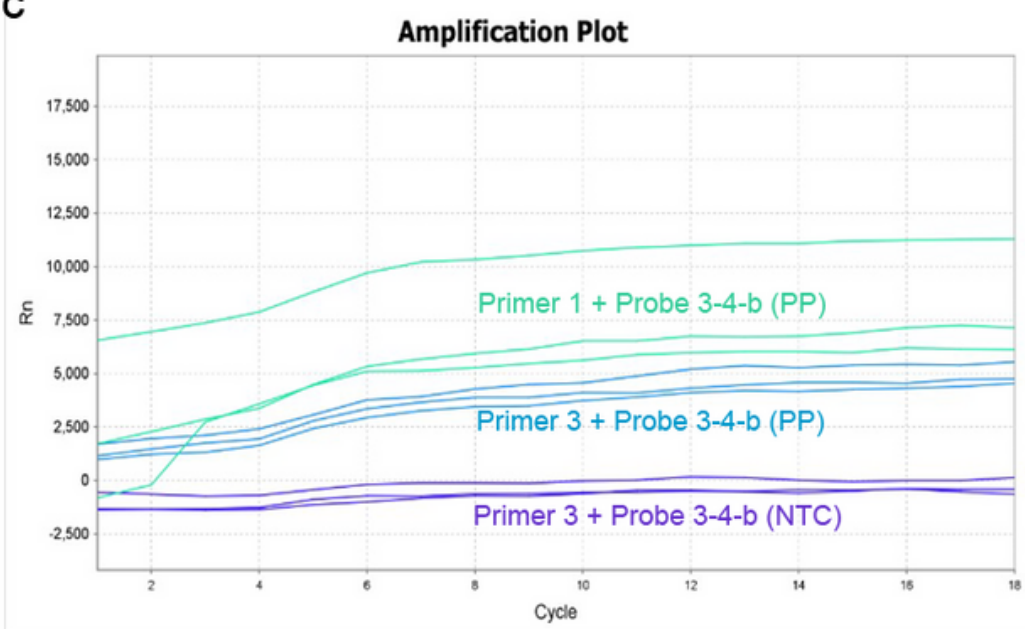

\section{Figure 5}

Fluorescence amplification curve of primer and probe combination. a The fluorescence amplification curve of Primer1+Probe1 combination, the fluorescence value of amplification is very high in the positive plasmid control of T. gondii for three repeats. b The fluorescence amplification curve of Primer1+ Probe34-a and Primer3+ Probe3-4-a, there are no significant amplification, and the consistency is poor for three repeats. c The fluorescence amplification curve of Primer1+ Probe3-4-b and Primer3+ Probe3-4-b, there 
are no significant amplification, and the amplification consistency of Primer1+ Probe3-4-b is poor for three repeats. Abbreviations: PP, positive plasmid control; NTC, negative control.

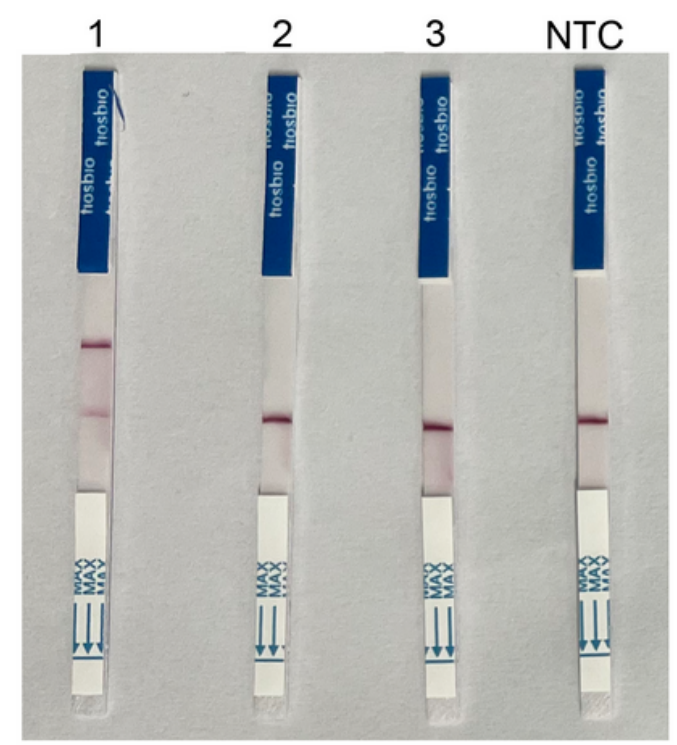

$20 \min$

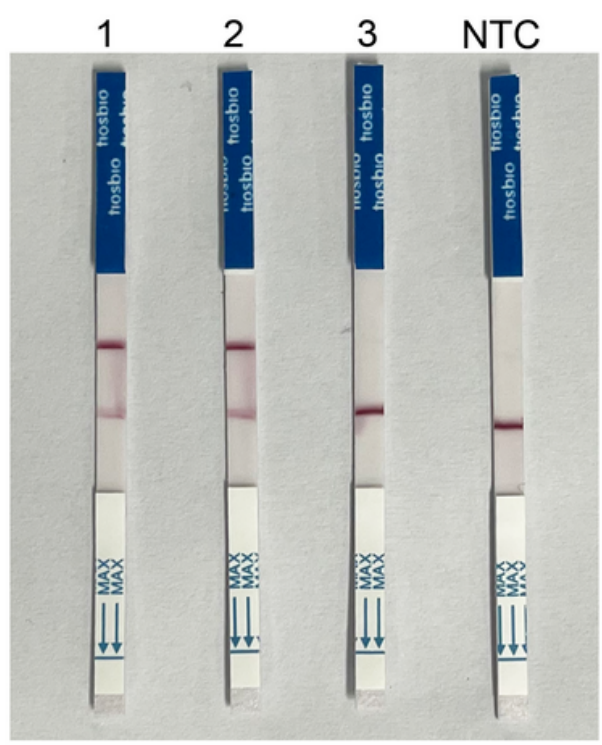

$30 \min$

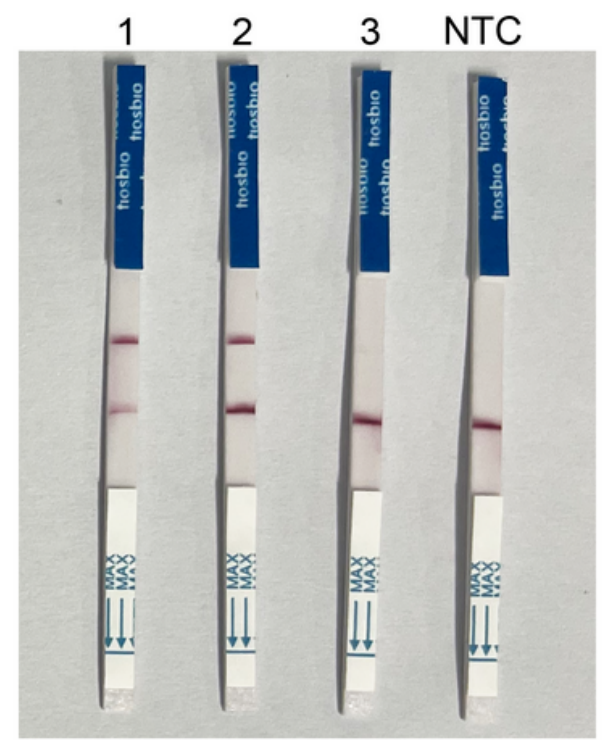

$40 \min$

Figure 6

Optimization result of RAA-Cas13a-LFD amplification time. Strips: $1.1 \times 10-5 \mathrm{ng} / \mu \mathrm{L} ; 2.1 \times 10-6 \mathrm{ng} / \mu \mathrm{L} ; 3$. $1 \times 10-7 \mathrm{ng} / \mu \mathrm{L}$; NTC, negative control (ddH2O). 

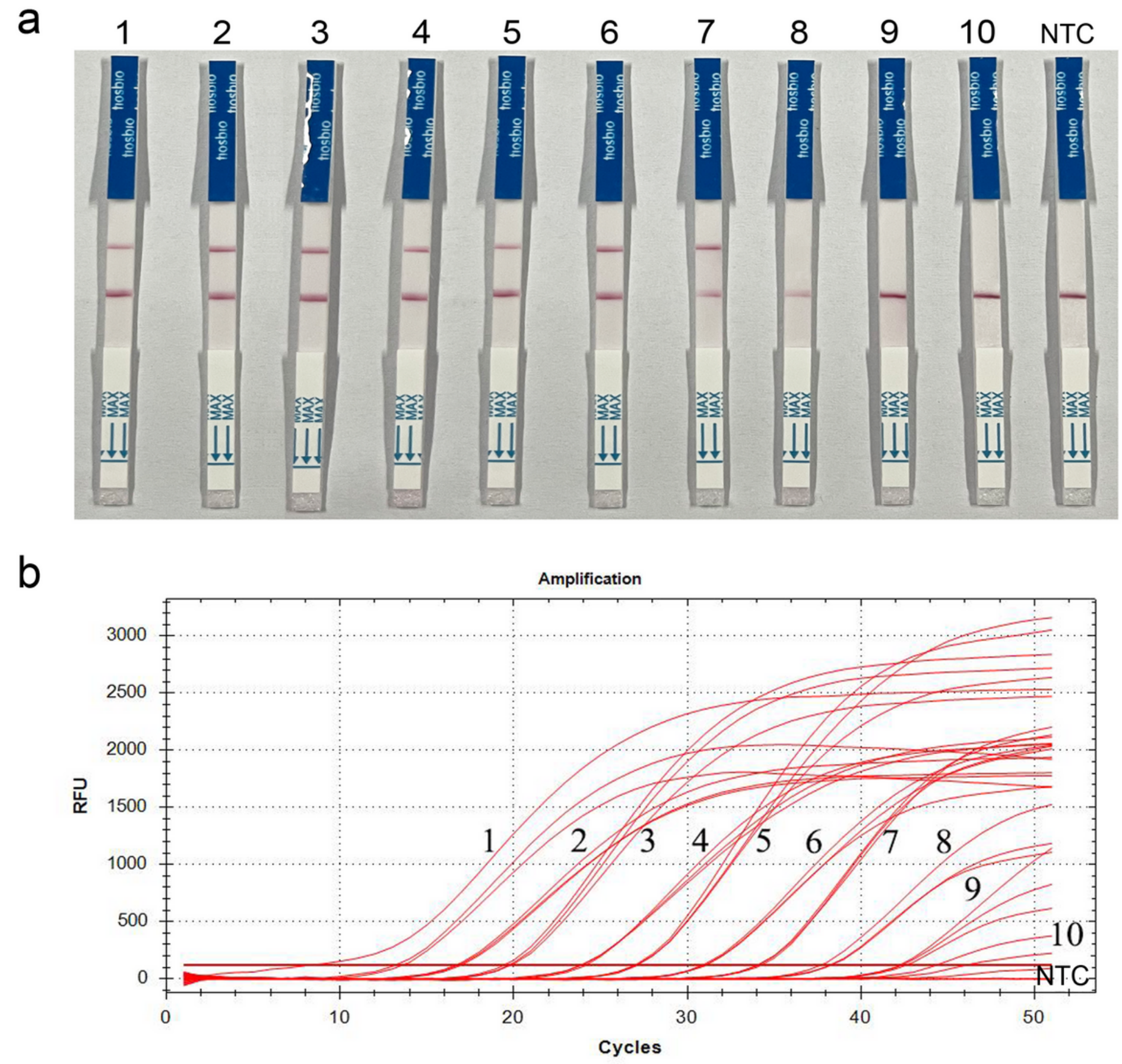

Figure 7

The sensitivity of RAA-Cas13a-LFD and qPCR detection methods for T. gondii. a Visual inspection of RAACas13a-LFD. b Curves for qPCR. Strip and curves: 1-10: plasmid copy number diluted to $1 \mathrm{ng} / \mu \mathrm{L}-1 \times 10-9$ $\mathrm{ng} / \mu \mathrm{L}$, respectively; NTC, negative control (ddH2O). 


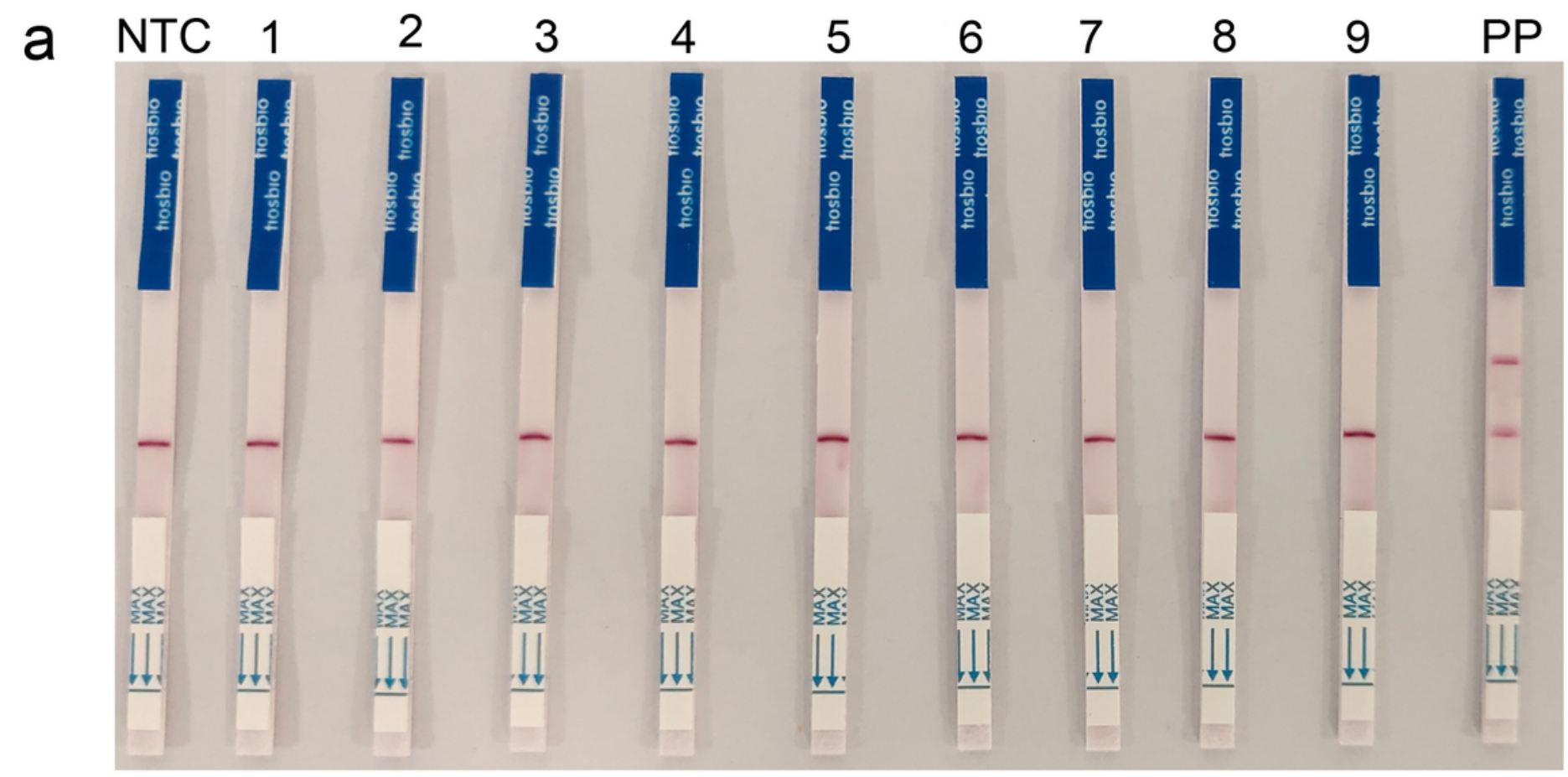

b

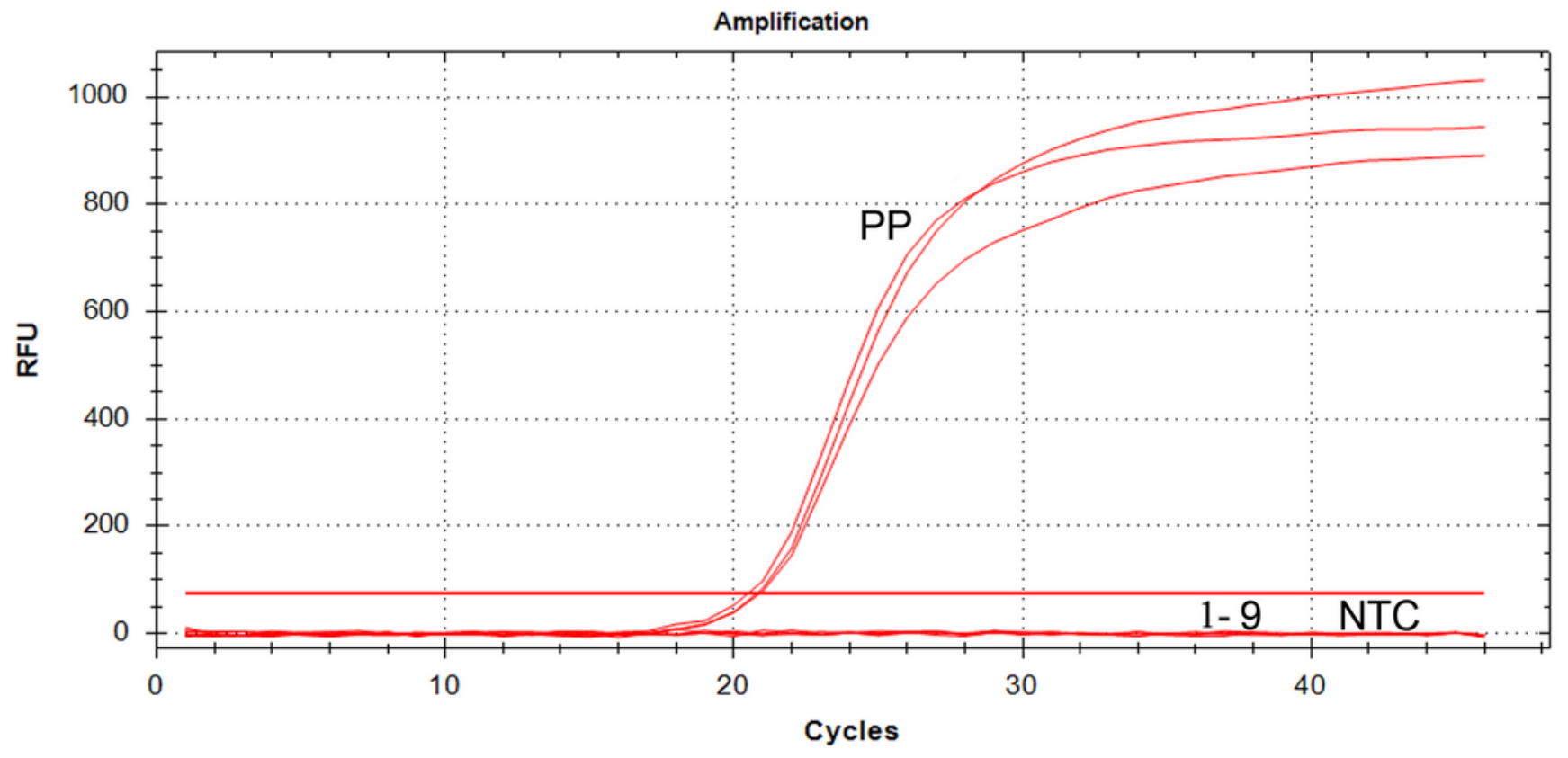

\section{Figure 8}

The specificity of RAA-LFD and qPCR detection methods for T. gondii. a Visual inspection of RAA-Cas13aLFD. b Curves for qPCR. Strip and curves: 1. Human blood; 2. Ascaris lumbricoides; 3. Digramma interrupta; 4. Entamoeba coli; 5. Fasciola gigantica; 6. Plasmodium vivax; 7. Schistosoma japonicum; 8. Taenia solium; 9. Trichinella spiralis; Abbreviations: PP, Positive plasmid of T. gondii; NTC, negative control (ddH2O) 


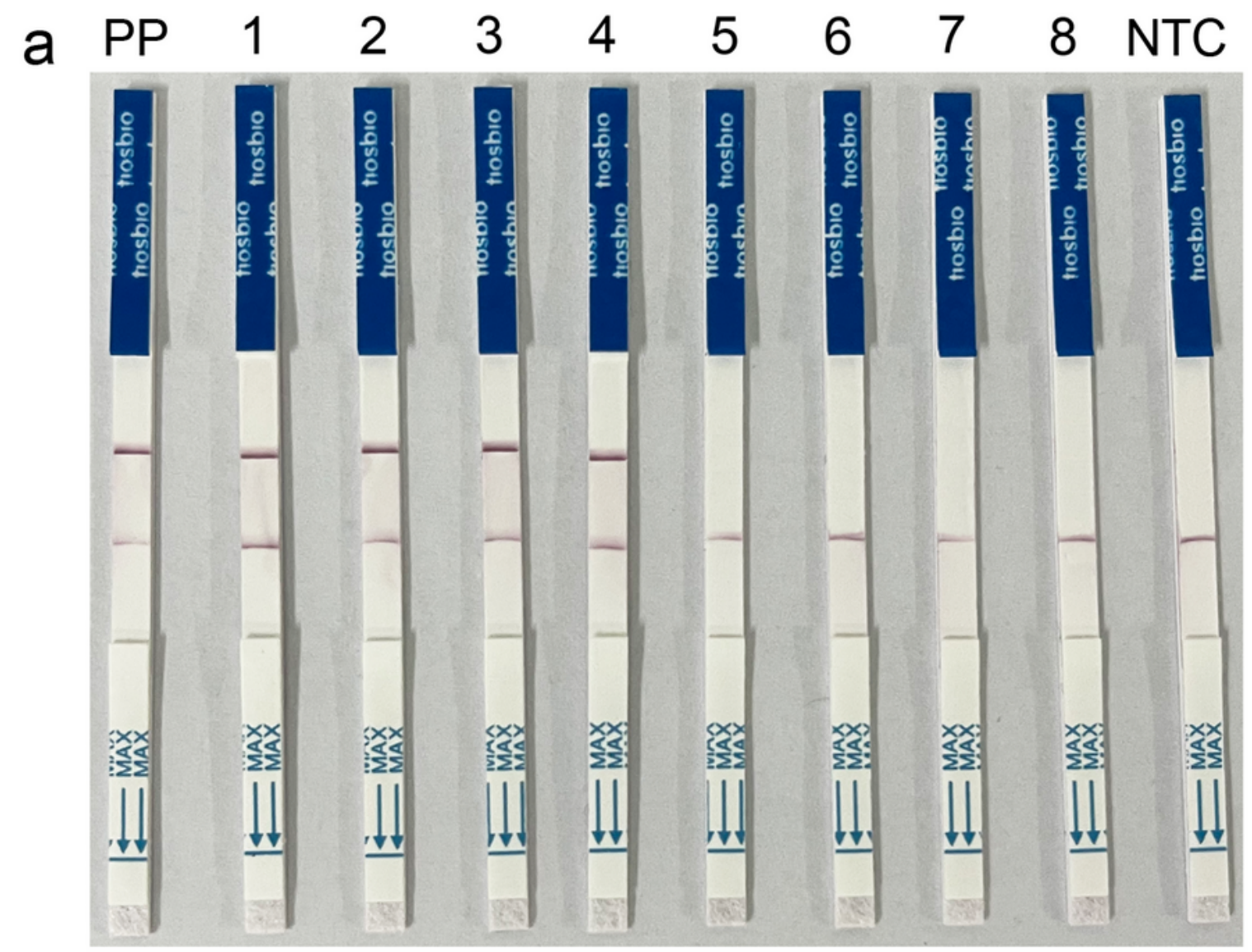

b

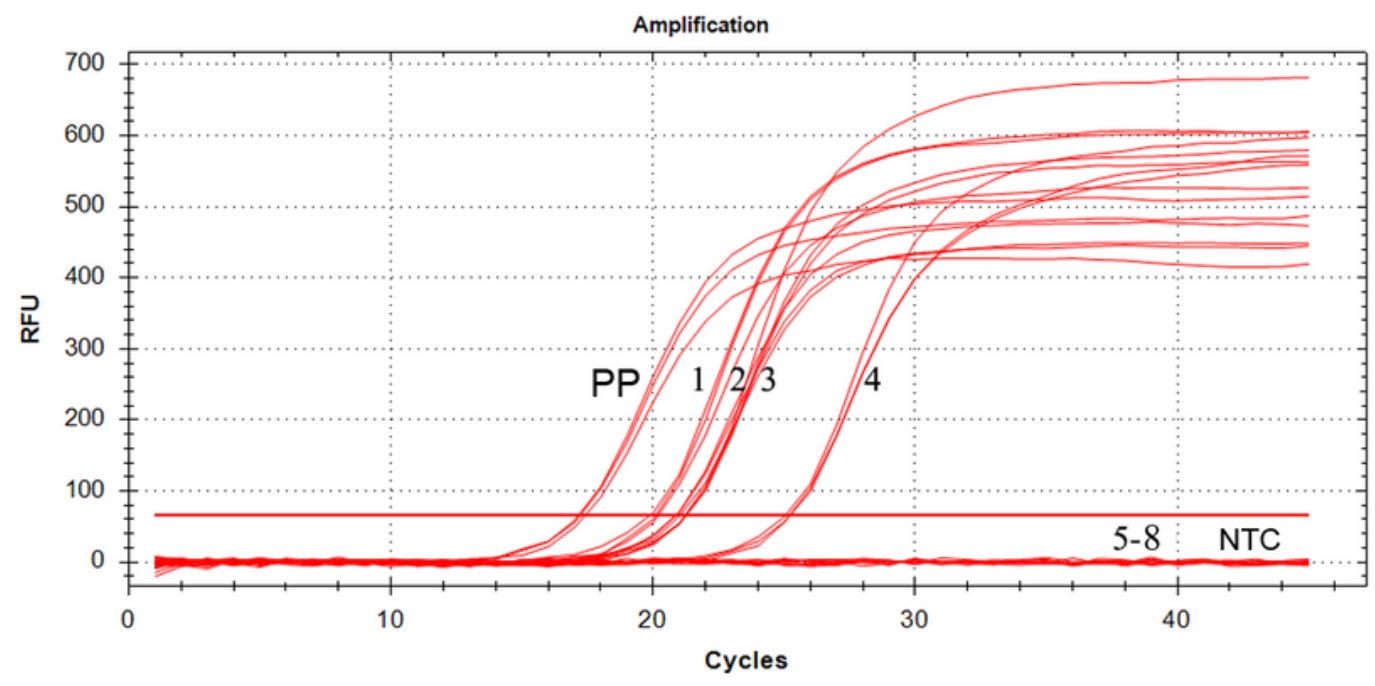

Figure 9

Detection of blood samples of RAA-Cas13a-LFD and qPCR methods for T. gondii. a Visual inspection of RAA-Cas13a-LFD. b Curves for qPCR. Strip and curves: 1-4: positive sample; 5-8: negative samples; Abbreviations: PP, Positive plasmid of T. gondii; NTC, negative control (ddH2O)

\section{Supplementary Files}


This is a list of supplementary files associated with this preprint. Click to download.

- GraphicalAbstract.tif 